\title{
Subglottic Chicken Bone in a Five Months old Baby
}

\author{
Prakash $\mathrm{S}^{1}$ Bhusal $\mathrm{CL},{ }^{1}$ Acharya $\mathrm{K}^{\prime}$ Sinha BK' \\ 'Ganesh Man Singh Memorial Academy (GMSMA) of ENT and HN studies, Institute of Medicine (IOM), Maharajguni, \\ Kathmandu, Nepal
}

\section{ABSTRACT}

Foreign body aspiration most commonly affects young children, with respiratory symptoms such as wheeze and cough after a choking episode. When the foreign body is first inhaled as per witnessed by the parents or caregiver there is always choking or gaging episode, followed by a coughing spell. The absence of a cough strongly rules out the possibility of foreign body having entered the air passage. Here we report a case of chicken bone inhaled as foreign body in a five months old baby.

Key Words: bone, chicken, subglottic

\section{INTRODUCTION}

Inhalation of foreign body (FB) in children is not an uncommon occurrence. ${ }^{1}$ A careful history and clinical examination can identify those children that need additional investigation including bronchoscopy. ${ }^{2}$ It can only enter the air passage if there is some interference with the normal reflex action, such as sudden inspiration while eating, playing, fright or laughter. ${ }^{3} \mathrm{FB}$ aspiration is a severe and sometime potentially fatal occurrence in childhood ${ }^{4}$ It remains in trachea when the size of foreign body is greater than the tracheal lumen or in cases of sharp foreign body which gets impacted in trachea. As the it moves distally in the air way, the symptoms often became less apparent and may even subside, creating a great diagnosis challenge because the remainder of the assessment, mainly the physical examination and radiography can be deceptively normal. ${ }^{5}$

\section{CASE REPORT}

A five months male child presented in a paediatric hospital with the sudden episode of choking, breathing difficulty, noisy breathing, excessive crying and increased salivation since one day, after her mother gave rice bolus in the night. He was then started with intra venous antibiotics, continuous oxygen through nasal prongs and nebulisation with Asthalin in the wake of Aspiration pneumonia. Patient also developed fever next day then transfer to intensive care unit for observation. After three days of admission, patient was shifted to Paediatric Unit of ENT and Head and Neck Department of Teaching Hospital for further management. There was noisy breathing and chest indrawing. The bilateral air entry was equal but wheeze could be heard. Chest $X$-ray was normal (Figure 1). Oxygen saturation was $100 \%$ with continuous oxygen, pulse was 160 per minute, respiratory rate was 44 per minute, heart rate
Correspondence:

Dr. Sanjay Prakash

Ganesh Man Singh Memorial Academy (GMSMA) of

ENT and HN Studies, Institute of Medicine

Maharajgunj, Kathmandu, Nepal

Email: drsanjay.prakash@gmail.com 
was 160 per minute and Blood pressure of $117 / 58 \mathrm{~mm}$ of $\mathrm{Hg}$. After consultation in ENT Department, diagnosed as a case of airway foreign body with positive history and planned for diagnostic bronchoscopy and removal of foreign body if present. Basic investigationswas done for general anaesthetic fitness and patients shifted to operation theatre. While intubating the baby, endotracheal tube could not be negotiated in trachea. Rigid Bronchoscope introduced and a hard foreign body was detected in the subglottis area. After several attempts, it could not be grasped with forceps because it was sitting tightly in the subglottic space. Oxygen saturation could not be maintained properly. Immediate tracheostomy was done on the table with combined decision with anaesthetist (Figure 2). After maintaining the saturation, Rigid bronchoscope was introduced again to locate the foreign body. Finding the small lumen of the larynx, it was decided to put direct laryngoscope. With the use of forcep and endoscope, foreign body was removed under direct vision. On per-operative finding, it was a $2 \times 1 \mathrm{~cm}$ piece of chicken bone with sharp one end present just below the glottis (Figure 3). Patient was again kept in Paediatric intensive care unit for 2 days for observation. Decannulation was done after corking for 2 more days. On further follow up, he was absolutely fine.

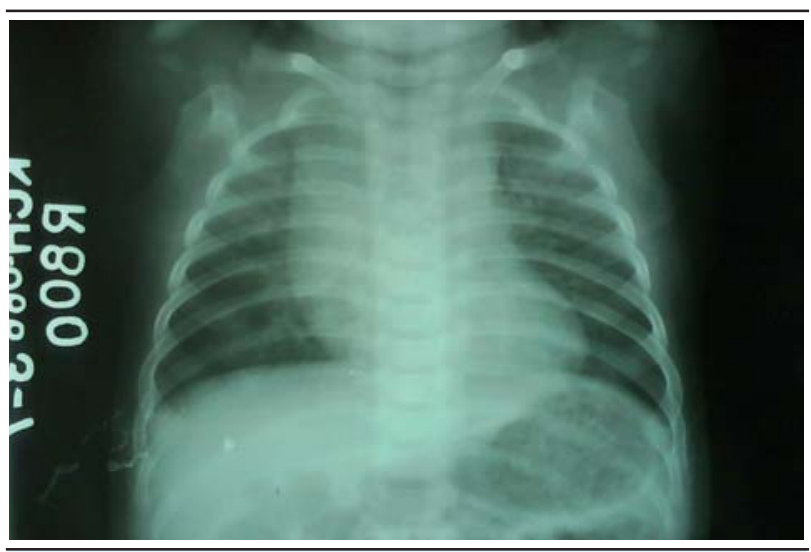

Figure 1. Normal chest X-ray

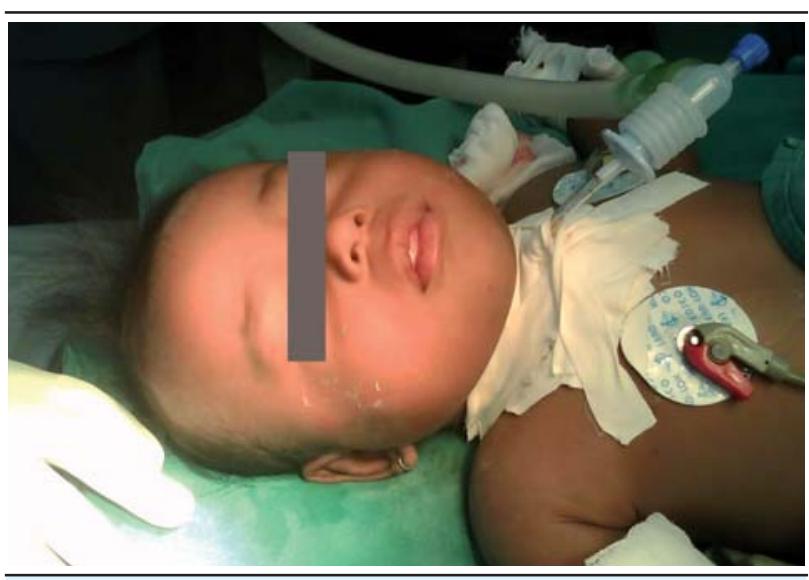

Figure 2. Tracheostomy

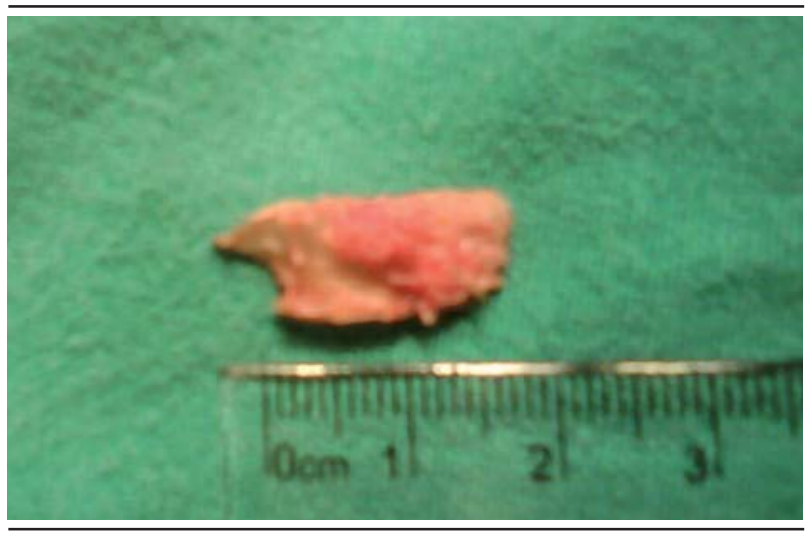

Figure 3. Foreign body chicken bone

\section{DISCUSSION}

The incidence of foreign body in food passage is more common than in the air passage.$^{6}$ The position of foreign body depends upon its relative size. There can be foreign body reaction depending upon the size and the nature of foreign body. Peanuts, Seeds, Beans and other organic objects may cause significant tissue reaction having a rapid clinical deterioration. According to Shah et $\mathrm{al}^{7}{ }^{7}$ it is necessary to screen and X-ray every patient who is admitted with a history of having swallowed a foreign body or patient who suddenly develops cough and dyspnoea. Linegar and colleagues ${ }^{8}$ reported that among children who had a positive clinical history and a negative chest radiograph and physical examination, there was a $45 \%$ incidence of foreign bodies on ear way endoscopy. Compared with history and physical examination, radiography appears to be a least sensitive in predicting bronchoscopy findings. ${ }^{9}$ Possibility of foreign body must be kept in mind where patient is brought with symptoms such as respiratory distress or loss of voice with a history of loss of consciousness. In our case, the baby presented with all positive findings of airway foreign body. The foreign body was chicken bone which was almost rectangular in shape, approximately $2 \times 1$ centimetre in size (Figure 3 ). It was in coronal plane and the upper end was lying just below the true cords. The largest dimension of foreign body was greater than the subglottic diameter. So it was lodged in subglottis. Being vertically placed in subglottis, it did not produce total collapse of the airway as small lumen for airway was patent in both the side of foreign body. By passage of time, foreign body would have produced edema and granulation tissue in subglottic area leading to subglottic stenosis and further increase in respiratory distress and stridor. ${ }^{10}$ It is not uncommon to feed the baby at the age of five months or before in our country despite of advocating absolute breast feeding till six months. Such incident will occur more frequently and the health of the baby may be jeopardize if awareness level is not improved in the parents and health professionals. 


\section{REFERENCES}

1. Tan HKK, Brown K, McGill T, et al. Airway foreign bodies (FB): a 10 year review. Int J Pediatr Otorhinolaryngol. 2000;56:91.

2. S, Monetti C, Meneghini L, et al. Eight years' experience with foreign body aspiration in children: what is really important for a timely diagnosis? J Pediatr Surg. 1999;34:1229.

3. Gupta IP, Sood VP. Foreign body in the air passages. Ind J Otolaryngology. 1967;19:173-4.

4. HughesCA, BaroodyFM,Marsh BR.Pediatric tracheobronchial foreign bodies: historical review from the Johns Hopkins Hospital. Ann Otol Rhinol Laryngol. 1996 Jul;105(7):555-61.

5. Barrios Fontobe JF, Gutierrez C, Lluna J, et al. Bronchial Foreign body; should Bronchoscopy be performed in all kpatients with choking crisis? Pediatr Surg Int. 1997;12(23):118-20.
6. Sambamurty V,Ramanjaneyalu P,Ramachary V. Foreign body in food and air passage. Ind J Otolaryngology. 1971;23:84-7.

7. Shah KU, Kherewala SDD, Pardiwala HA. A bronchial foreign body producing dysphagia. Ind J Otolaryngology. 1968;20s:38-40.

8. Linegar AG, Von Oppell UO, Hegemann S, et al. Tracheobronchial foreign bodies Experience at Red Cross Children's Hospital, 1985-1990. S Afr Med J. 1992;82(3):164-7.

9. Ciftci AO, Bingol-Kololo M, Senocak ME, et al. Bronchoscopy for evaluation of foreign body aspiration in children. J Pediatr Surg. 2003;38(8):1170-6.

10. Farooqui TUH, Ahmad I, Hasan S, Khan MI. Management of Subglottic Foreign Body. J Coll Physicians Surg Pak 1999 Apr;9(4):184-6. 